tial diagnoses included hypomania and drug addiction. Eventually a test was done and carbimazole prescribed. So far he hasn't relapsed.

\section{The public's reactions}

Our national game is not cricket, it is writing letters to The Archers. My favourite came from the senior common room of a Cambridge college, inquiring whether Kenton and Shula are monozygotic or dizygotic twins. As Kenton is a boy and Shula a girl.... Congratulatory letters came particularly about Walter Gabriel's death, the evolution of Peggy's polymyalgia rheumatica, and Shula. Many letters were sad-for example, from women whose diagnosis of polymyalgia had been long delayed.

Letters from doctors criticised Matthew or suggested interesting diseases for Ambridge folk to develop. Many pressure groups wrote asking for publicity. Usually they came too late. There was one from the hare lip people, but we didn't write back "congratulations you've hit the jackpot." Other vested interests wrote-drug firms to say that their hay fever tablets didn't cause drowsiness and pharmacists complaining that Shula and Jennifer Aldridge went to the doctor and not the chemist for a pregnancy test.

Reactions in the press were usually sympathetic. I particularly looked forward to Dr Tom Stuttaford's The Times medical briefing a couple of weeks after a story.

My bosses were tolerant and usually interested and amused. Some tried to get me to spill the beans. One affected uninterest and intellectual snobbery about it, but he often knew what was happening-a closet Archers fan. Writing articles for specialist journals gave him an audience of a few thousand at best, whereas The Archers could aim to influence over six million listeners.

The Archers was conceived as an educational exercise to teach city folk about farmers' problems. Although primarily an entertainment, it allows some public education, but how effectively? Angie's overdose on EastEnders was studied retrospectively. ${ }^{2}$ Our prospective study of the effect in the West Midlands of Peggy Archer's polymyalgia rheumatica was not a success. ${ }^{3}$

\section{Handing over to a real GP}

I moved to Glasgow and offered to resign but carried on for a while. Eventually, it got too difficult. Although disappointed to leave, I was glad to hand over to a close friend who is a real Borcetshire general practitioner. I had a lot of fun and met excellent people. It certainly gave me something unexpected to talk about at dinner parties and job interviews.

The straightforward things I learnt were about aspects of medicine that cropped up, a bit about drama, broadcasting, and the BBC. I sometimes use words like subtext now. Most importantly, doctors normally deal with disease and struggle to understand the consequences to patients and their families. Here it was the other way round-diseases designed for their consequences. It has broken the magic of The Archers for me. I can't really believe it any more. I know that it's all made up and can see actors in the studio when I'm supposed to be in The Bull or a milking parlour. I still enjoy soaps, especially Brookside, wich is set in my home town.

I should like to thank all the friends and colleagues who helped me with advice, suggesting stories, or simply tolerating my occasional absences and telephone conversations. I was enjoying myself in a fantasy world while they did the real work in the real world.

1 Bamii A. Medicine and the media. BrMed f 1987;295:1055.

2 Platt $S$. The aftermath of Angie's overdose: is soap (opera) to your health? BrMed f 1987;294:954-7.

3 Symmons DPM, Dover SB, Murray AJ. Polymyalgia rheumatica-did Peggy's plight have any impact? Birmingham: Midlands Rheumatological Society, 1988

\title{
Cutting prescribing costs: learning from Birmingham in 1913
}

\section{Guy Houghton}

In 1911 Lloyd George introduced the National Insurance Act through parliament. This was intended to organise basic medical cover for the employed population earning less than $£ 2$ a week by a system of compulsory medical insurance. These lower wage earners would then be able to join the panel of a general practitioner, who would treat them along with his private patients and those who had independent insurance through "sick clubs" and friendly societies.'

There had been no prior consultation with the profession, and there was no provision for medical involvement in administering the scheme. The act was soon found to be unworkable without the cooperation of the doctors, and local elected representative bodies were required with official recognition. ${ }^{2}$ Statutory local medical committees were instituted under Clause 62 of the act to represent general practitioners in the district of each health committee. By January 1913 the Birmingham Local Medical Committee was recognised by the National Health Insurance Commission. At the third meeting of this statutory local medical committee on 6 May 1913 a pharmacopoeia subcommittee was formed to advise on prescribing and liaise with the local chemists. They would also be responsible for analysing prescriptions submitted from the insurance committee to keep prescribing costs at a reasonable level and curb extravagant prescribing. With the cooperation of the Midland Pharmaceutical Association a local pharmacopoeia of stock mixtures was drawn up for use by all panel doctors. By 14 June 1913, 500 copies had been sold and it had saved considerable time in prescription writing as well as standardising dispensing.

On 8 September 1913 the chemists of the city met with the pharmacopoeia subcommittee as prescribing costs were in danger of overrunning the insurance budget. In the second quarter of 1913, 237000 prescriptions had been dispensed, at an average cost of $81 / 4 \mathrm{~d}$ each (about $3 \mathrm{p}$ ). It was agreed that a limited list was required to reduce costs, following the example of Essex. The medical benefit subcommittee on the advice of the local pharmaceutical and local medical committees in that county had imposed restrictions disallowing oxygen, sera, vaccines, various foods, and also such surgical supplies as elastic stockings and kneecaps, spectacles, trusses, eyeshades, lamps, and clinical thermometers. This was published in the $B M F$ in August 1913. The Birmingham list did not disallow the surgical items but instead anticipated the generic substitution of today by requesting that "Proprietary articles should not be prescribed when similar preparation is widely known." Figure 1 shows the full list. Furthermore, the panel practitioners were informed 
1. The supply of the undermentioned articles is disallowed:-

(a) Oxygen, (b) Vaccines, (c) Sera, (d) Wincarnis.

(e) All Foods, such as "Allenbury's Diet," “Benger's,"

“Bovril," “Invalid Bovril," “Jellies,” “Liebig's Extract

of Meat," "Plasmon Biscuits and Cocoa," "Sanatogen,"

“Valentine's Meat Juice," “Virol,” and other similar

preparations.

2. Proprietary articles should not be prescribed when a similar preparation is widely known-as examples:-

NOT ANGIER'S EMULSION

„ SCOTT'S EMULSION

„ VASELINE

„ PAROLEINE OR PEROL

, IODINE VASOGEN

„ UROTROPINE or METRAMINE

” DIURETIN

, ASPIRIN

„ FORMAMINT

” PURGEN

” TABLOIDS, SOLOIDS, SOLVETTES, VARALETTES or PALATINOIDS
BUT PETROLEUM EMULSION.

„ COD LIVER OIL EMULSION.

„SOFT PARAFFIN.

„ OL. PARAFF. LIQ.

„ PAROGEN IODI., B.P.C.

„ FORMAMINE.

„ THEOBROMINE SODIO-SALICYLATE.

„ ACETYL-SALICYLIC ACID.

„ FORMALIN TABLETS.

„ PHENOLPHTHALEIN TABLE'TS.

„ TABLETS, CAPSULES or CACHETS.

26th September, 1913.
FIG 1-List of proprietary articles not to be used that repeat prescriptions written only as "Rep Mist" (that is, the chemist was to make up a further bottle of whatever mixture the patient had last been prescribed) would no longer be paid for by the insurance committee. Not only would this reduce possible dispensing error but also discourage unnecessary and slipshod prescribing.

These economy measures met with surprisingly little reaction. Only one practitioner wrote back to the local medical committee to complain "I find the results obtained by using the drugs I order superior to those from the drugs you suggest. As regards the floating $6 \mathrm{~d}$ [the contingency sum per patient set aside by the insurance committee to cover unbudgeted excess expenses] it does not interest me." One London pharmaceutical company contacted the Birmingham Medical Committee to maintain the fact that "Our Palatinoids are better than compressed tablets or paste made pills ... has been fully established by the most eminent medical, chemical and pharmaceutical authorities in practically all parts of the world.... There are no equivalents to any of our principal products. They are all original and they have no imitations. The Bipalatinoids, Palatinoids and Pulverettes, by the recent International Pharmaceutical Congress held in Vienna, were awarded the large gold medal for their high character, therapeutically and originality." No further contrary views were expressed and the concept of the limited list and non-proprietary prescribing seemed to be accepted in Birmingham.

Despite these economy measures the Birmingham Health Insurance Committee still found it necessary to write to the local medical committee on 17 March 1914 about the prescribing bill. "The cost of the drugs prescribed during the year ended January 11 last was greatly in excess of the amount available in the Drug Fund. According to the accounts rendered by the chemists during the current year the cost is rapidly increasing. ... The Insurance Committee hope that the Local Medical Committee will deal with this question at the earliest possible moment." By 5 October 1914 the pharmacopoeia subcommittee was able to report that it had met on two occasions and examined the analysis of prescriptions submitted by the insurance committee for the year ending 14 January 1914.

We have examined a number of prescriptions and find that certain individual prescriptions are definitely extravagant; others contain expensive ingredients when cheaper preparations would be equally efficacious; others again consist of a large number of unnecessary ingredients often antagonistic from a therapeutic point of view. Judged by the standard of their colleagues, and the general average throughout the country, such prescriptions are unnecessarily costly. As the result of a careful analysis your Committee recommends that all Panel Practitioners whose expenditure on drugs has 
exceeded one shilling and sixpence per insured person on his list for the half year under consideration, be surcharged. In view of the possible general ignorance of the cost of dispensing under the present tariff, we recommend that the surcharge be in each case half the amount by which they have exceeded one shilling and sixpence for the said half year. Your Committee further recommend that every Practitioner whose average cost of prescription exceeds ninepence, and whose cost per insured person on his list exceeds one shilling for the half year be warned. Also, that a statement be sent to each Panel Practitioner showing:

(a) number of patients on his list

(b) number of prescriptions issued

(c) average cost of prescriptions

(d) average cost per insured patient on his list

(e) total cost of his prescriptions

(f) average cost of prescriptions in Birmingham

(g) average cost of prescriptions in the country

(h) average number of prescriptions per insured person in Birmingham.

This precursor of PACT (prescribing analysis and cost $)^{3}$ was to be funded by the insurance committee paying one half and the panel and pharmaceutical committees each a quarter of the total cost of analysis. Birmingham insisted that all 365 days of prescriptions should be analysed, whereas the London panel worked only on 19 representative days.

On 15 October 1914 the Birmingham Panel Committee wrote to all overspending practitioners. The panel committee was in a way the forerunner of the executive council/family practitioner committee and had lay and professional representatives. A letter (fig 2) was sent after a meeting with the pharmacopoeia

\section{Birmingham Panel Committee.}

\section{NATIONAL HEALTH InSURANCE (Medical Benefit) REGULATIONS.}

$$
\begin{aligned}
& \text { 1, Bourngkook Road, } \\
& \text { Seli. PakK, } \\
& \text { October 15th, 19/4. }
\end{aligned}
$$$$
\text { DeAR SIR, }
$$

I beg to draw your attention to Article 40 of the above Regulations. which is printed below :-

(1) "Where it appears to the Panel Committee that by reason of the character or amount of drugs or appliances ordered for insured persons by any practitioner or practitioners on the papi, the cost of the supply of those drugs and appliances is in excess of on the panel, the cost of the supply of those drugs and appliances is in excess of what may reasonably be necessary for the adequate treatment of those persons, the Panel Committee may, and if any representations to that effect are made to them by the Pharmaceutical Committee, shall make an investigation into the circumstances of the case, whether in respect of the drugs and appliances ordered by an individual practitioner or generally as to the orders given for drugs and appliances by practitioners on the panel."

(2) "The Panel Committee shall, after hearing the Pharmaceutical Committee and any practitioner concerned, make a report to the Committee, and if, after considering the report, the Committtee are of.opinion that an excessive demand upon the Drug Fund has arisen owing to orders given by a practitioner which are extravagant either in claracter or in quantity they may, if they think fit, make such deduction from the amount payable to that practitioner by the Committee as they think fit and

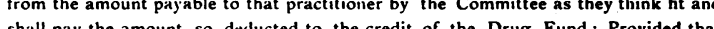
shall pay the amout so deducted to the credil of the Drug Fund: Provided that the practitioner shall be entitled to appeal to the Commissioners, whose decision
shall be final."

At the request of the Pharmaceutical Committee, the Panel Committee have made a very careful investigation of the prescriptions issued by all Panel Practitioners during the latter half of the year 1913, and have decided (in accordance with the above Article) to recommend the Insurance Committee to surcharge any practitioner whose prescriptions have exceeded in average cost per insured person on his list, the sum of one shilling and sixpence for the half year under consideration.

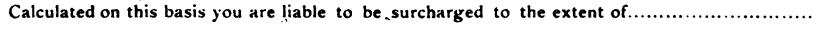

If you wish to offer any explanation or defence, please let me know by the 24th inst., when will notify you of the time and place at which the Panel Conmittee will be prepared to hear you.

Yours faithfully,

WILLIAM J. GARBUTT, Hon. Sec. subcommittee from the local medical committee. The meeting had heard that certain doctors had already informed their patients that they were prohibited from ordering proper medicines and if they did so they would be surcharged. The insurance committee was anxious to prevent extravagance in any direction, but it was clear that great care had been taken to avoid exaggerated views being taken by practitioners in doing their work. Given, firstly, that the act was new and the panel practitioners were not fully aware of the charges that would be incurred by working on the new drug tariff; secondly, that doctors who had previously dispensed their own mixtures bought in bulk would not have appreciated that the separate costing under the tariff would be out of proportion to their previous costs; and, thirdly, that the local pharmacopoeia had been found to be more costly in practice than anticipated the panel committee decided not to consider for the year 1913 any practitioner as guilty of excessive prescribing who had not exceeded three shillings per insured patient.

Thirty four practitioners were found to have exceeded this cost in 1913. All cases were carefully investigated and their prescriptions examined. They were each invited to give an explanation of any special circumstances to account for their high prescribing costs and to attend the panel committee in person if they wanted to justify themselves. As a result 26 practitioners attended a hearing. The panel committee exonerated 18 of these, even though they had exceeded the cost per insured person. The committee did, however, consider that excessive prescribing was proved in 16 cases. Table I shows the details with explanations of the excess, and the recommended surcharges, which varied from a half to a sixth of the overspending, depending on the average cost of each prescription over the year or half year, are shown in table II.

By September 1915, however, the pharmacopoeia subcommittee met again to analyse the 1915 prescriptions. As the results were similar to those from 1914 and 1913 and there had been distinct general improvement in prescribing over the first quarter the committee thought it could inform the panel committee that it was inadvisable to recommend surcharge in the case of any practitioner. Twelve doctors were, however, interviewed and a further 20 were written to about "general extravagance." In 1916 only two doctors were invited to appear before the panel committee and letters of warning were sent to four. The two were appropriately surcharged after interview the sum of $£ 315$ s 0 d and $£ 18$ respectively.

Seventy five years on there are clear immediate parallels. The minister of health aimed at modifying prescribing costs by introducing a limited list in $1985 .{ }^{4}$ In a similar way to the removal of foodstuffs from prescriptions for panel patients by the Birmingham Local Medical Committee, so cold remedies, simple analgesics, antacids, and laxatives were no longer available on FP10 forms. At the same time, just as Birmingham discouraged proprietary prescribing, the minister not only emphasised the financial advantages of generic prescriptions but even defined some treatments such as benzodiazepines and moderate strength analgesics in which drugs could be prescribed only under approved names. The emphasis today is on indicative drug budgets, though the implications of this budget seem to be open to differing interpretations. ${ }^{5}$ Standing regulations at present derive from the surcharging mechanisms described in this paper. The secretary of state has the power to refer excessively prescribing doctors to the appropriate local medical committee, which decides a reasonable estimate of the excess cost incurred and can recommend a withholding of money from the doctor concerned to the 


\begin{tabular}{|c|c|c|c|c|c|c|}
\hline $\begin{array}{l}\text { No of } \\
\text { doctor }\end{array}$ & $\begin{array}{l}\text { No of } \\
\text { insured } \\
\text { people } \\
\text { on list }\end{array}$ & $\begin{array}{l}\text { No of } \\
\text { prescriptions } \\
\text { issued in } \\
1913\end{array}$ & $\begin{array}{l}\text { Cost per } \\
\text { insured person } \\
\text { on list } \\
(\mathrm{sd})\end{array}$ & $\begin{array}{l}\text { Average } \\
\text { cost of } \\
\text { prescriptions } \\
(\mathrm{s} \mathrm{d})\end{array}$ & $\begin{array}{c}\text { No of } \\
\text { prescriptions } \\
\text { per insured person } \\
\text { on list }\end{array}$ & Comments \\
\hline 1 & 2144 & 6422 & $453 / 4$ & 16 & $3 \cdot 0$ & Committee thought that gross extravagance had been committed \\
\hline 2 & 4011 & 14637 & $35 \frac{1}{2}$ & $11 \frac{1 / 2}{2}$ & $3 \cdot 6$ & Doctor pleaded ignorance in tariff, bad lives, and poor neighbourhood \\
\hline 3 & 1436 & 4480 & $323 / 4$ & $10 \frac{1 / 2}{2}$ & $3 \cdot 1$ & Doctor prescribed extravagantly in using unnecessary number of ingredients \\
\hline 4 & 1302 & 6555 & $381 / 4$ & $83 / 4$ & $5 \cdot 0$ & $\begin{array}{l}\text { Doctor had been unduly liberal in prescribing; complained he was newcomer and had lot of bad } \\
\text { lives }\end{array}$ \\
\hline 5 & 2100 & 8762 & 40 & $11 \frac{1}{2}$ & $4 \cdot 2$ & Doctor had been unduly liberal and had lot of bad lives \\
\hline 6 & 1227 & 5335 & $36^{1 / 2}$ & $93 / 4$ & $4 \cdot 3$ & Doctor prescribed extravagantly in using unnecessary number of ingredients \\
\hline 7 & 1412 & 6296 & $44^{1 / 4}$ & $11 \frac{1}{2}$ & $4 \cdot 5$ & $\begin{array}{l}\text { Doctor ordered excessive quantities of malt and oil, practised in bad neighbourhood, and had } \\
\text { many bad lives }\end{array}$ \\
\hline 8 & 3956 & 14681 & $311 \frac{1}{2}$ & $103 / 4$ & $3 \cdot 7$ & $\begin{array}{l}\text { Doctor ordered excessive quantities of malt and oil, practised in bad neighbourhood, and had } \\
\text { many bad lives }\end{array}$ \\
\hline 9 & 1420 & 6285 & $371 / 2$ & $93 / 4$ & $4 \cdot 4$ & $\begin{array}{l}\text { Doctor welcomed investigation and admitted extravagance due to unnecessary number of } \\
\text { ingredients }\end{array}$ \\
\hline 10 & 754 & 3425 & $463 / 4$ & 10 & $4 \cdot 6$ & Extravagance due to ignorance of conditions \\
\hline 11 & 1369 & 7161 & $401 / 4$ & 9 & $5 \cdot 2$ & Prescriptions showed excess but doctor had many bad lives and practised in poor neighbourhood \\
\hline 12 & 2856 & 10130 & $32 \frac{1}{2}$ & $103 / 4$ & $3 \cdot 5$ & Prescriptions were extravagant but doctor practised in poor neighbourhood \\
\hline 13 & 1970 & 11228 & $363 / 4$ & $71 / 2$ & $5 \cdot 7$ & Extravagance due to doctor giving excessive number of prescriptions \\
\hline 14 & 85 & 351 & 36 & 10 & $4 \cdot 2$ & Doctor had been extravagant but had small panel ( 85 ) \\
\hline 15 & 2018 & 7010 & $331 / 2$ & $113 / 4$ & $3 \cdot 5$ & $\begin{array}{l}\text { Doctor had been extravagant but pleaded ignorance of tariff and complained that he had not been } \\
\text { told soon enough }\end{array}$ \\
\hline 16 & 1223 & 7340 & $361 / 4$ & 7 & $6 \cdot 0$ & Doctor had been extravagant in ordering malt and oil but practised in poor district \\
\hline
\end{tabular}

TABLE II -Surcharges recommended for doctors who overprescribed in 1913

\begin{tabular}{|c|c|c|c|}
\hline $\begin{array}{l}\text { No of } \\
\text { doctor }\end{array}$ & $\begin{array}{c}\text { Amount of excess for year } \\
(3 / \text { - per insured person }) \\
(£ s d)\end{array}$ & $\begin{array}{l}\text { Recommended } \\
\text { surcharge } \\
(£ \leq d)\end{array}$ & $\begin{array}{l}\text { Average cost of } \\
\text { prescription } \\
(\mathrm{sd})\end{array}$ \\
\hline 1 & 15900 & 79100 & $201 / 4$ \\
\hline 2 & 4700 & 11150 & $111 / 4$ \\
\hline 3 & 1600 & 400 & 12 \\
\hline 4 & $44 \quad 00$ & 1100 & $11^{3 / 4}$ \\
\hline 5 & $104 \quad 00$ & 2600 & 11 \\
\hline 6 & 3400 & 8100 & $10^{1 / 2}$ \\
\hline 7 & 9500 & 31134 & 13 \\
\hline 8 & 19300 & $64 \quad 63$ & $1 \quad 1 \frac{1}{2}$ \\
\hline 9 & $44 \quad 00$ & 1100 & 11 \\
\hline 10 & 5900 & 9168 & $101 / 4$ \\
\hline 11 & $62 \quad 00$ & 1068 & $9^{1 / 4}$ \\
\hline 12 & $30 \quad 00$ & 7100 & $11 \frac{1}{2}$ \\
\hline 13 & $56 \quad 00$ & 968 & 8 \\
\hline 14 & 226 & 107 & $10^{3 / 4}$ \\
\hline 15 & 2980 & 14140 & $10^{1 / 4}$ \\
\hline 16 & 30150 & 526 & 7 \\
\hline
\end{tabular}

family practitioner committee and the secretary of state. Should this local machinery be dismantled it will remove the local and peer influence that worked so well in 1914. This was well understood and appreciated by the panel committee of that day, who concluded that "It must, in such an investigation, be evident that any individual must be judged by the standard of his neighbours and the constitution of the Panel Committee made it inevitable that in every case there was present on the Panel Committee at least one man practising in the neighbourhood, who could offer first hand evidence to the nature and needs of the district." When the new family practitioner service authority under its new general manager with a single "independent" medical adviser, appointed and salaried by the authority, begins its administration of the new contract for general practitioners there will be no local practising professional representation on it and a considerable reduction in input from the statutory elected local medical committee without which Lloyd George found his National Insurance Act impossible to implement. Seventy five years ago professional self regulation was implemented at local level and accepted by practitioners with a minimum of complaint. Today there is lipservice to central negotiation and doctors are showing themselves less amenable to ministerial and managerial decree.

I thank Birmingham Local Medical Committee for my access to the minutes of the Birmingham Local Medical Committee and its pharmacopoeia subcommittee, 1913-4.

\section{Anonymous. History and structure of the general medical services. In: General practice: a great British success. London: General Medical Services Committee, British Medical Association, 1983:8-10. \\ 2 Marks J. The conference of local medical committee and its executive: an historical review. London: Trustees of the General Medical Services Defence Trust, 1979. \\ 3 Prescription Pricing Authority Information Services. PACT (prescribing analysis and cost). London: Department of Health and Social Security, 1988 4 Schedule 3A, regulation 2 (1) National Health Service (general medical and pharmaceutical services). London: HMSO, 1985. (Amendment regulation No 290:) \\ 5 Secretaries of State for Health, Wales, Northern Ireland, and Scotland. Working for patients. London: HMSO, 1989. (Cmnd 555.)}

\section{Health hazards in orthopaedic surgery}

The descriptions of health hazards in orthopaedic surgery in last year's christmas issue (BMF 1988;297: 1637-8) received attention in the national press, and the tale concerning the mouse in the theatre seems to have caught the popular imagination. This story bears such a resemblance to an occasion when I was present as house surgeon that I think it must be an account of the same event. Any readers who thought that exaggeration had crept in may be interested in the following details, which lend credence to an otherwise rather improbable story. Now that nearly 40 years have passed the episode is historical and I can name the participants without causing offence.

The date of the operation was 7 October 1949. It took place in one of the old general surgical theatres at the Royal United Hospital, Bath; these theatres had been erected during the first world war, and the money had run out before they could be rebuilt. Mr Herbert Fuller, then senior surgeon to the hospital, was approaching the end of a haemorrhoidectomy on a Methodist minister. The minister had been given a spinal anaesthetic by the senior anaesthetist, Dr Beddard, who could only be described as well built. The silence was broken by the appearance of a mouse, whose whereabouts were monitored by the patient. There followed a scuffle under the wash basins that lined one side of the theatre, from which Dr Beddard emerged triumphantly holding the mouse by its tail, having trapped it with his foot in the open drain that ran alongside the wall. "Well done!" cried the patient.

The operation was nearly over, and it was at this point that $\mathrm{Mr}$ Fuller's interest brought him suddenly to his feet, and he knocked himself out on the operating light. He was laid out on the floor temporarily while I inserted a tube into the patient and applied the dressings. "Are you all right, Mr Fuller?" the minister inquired anxiously as he was wheeled out of the theatre, followed shortly afterwards by the surgeon. Fortunately both made excellent recoveries, and the only loser was the mouse. Some years passed before the operating theatres were rebuilt. $-\mathrm{R}$ H C ROBINS orthopaedic surgeon, Royal Cornwall Hospital, Truro 